Article

\title{
Interactive Fuzzy Multi Criteria Decision Making Approach for Supplier Selection and Order Allocation in a Resilient Supply Chain
}

\author{
Sonia Irshad Mari ${ }^{1}{ }^{(0)}$, Muhammad Saad Memon ${ }^{1, *} *$, Muhammad Babar Ramzan ${ }^{2, *}$, \\ Sheheryar Mohsin Qureshi ${ }^{3}$ and Muhammad Waqas Iqbal ${ }^{4}$ \\ 1 Department of Industrial Engineering and Management, Mehran University of Engineering and Technology, \\ Jamshoro, Sindh 76062, Pakistan; sonia.irshad@faculty.muet.edu.pk \\ 2 Department of Garment Manufacturing, National Textile University, Faisalabad 37610, Pakistan \\ 3 Department of Industrial and Manufacturing Engineering, NED University of Engineering and Technology, \\ Karachi 75270, Pakistan; sheheryar@neduet.edu.pk \\ 4 Department of Industrial Engineering, Hongik University, Seoul 04066, Korea; waqastextilion@gmail.com \\ * Correspondence: saad.memon@faculty.muet.edu.pk (M.S.M.); babar_ramzan@yahoo.com (M.B.R.); \\ Tel.: +923-332-888-606 (M.S.M.)
}

Received: 24 December 2018; Accepted: 25 January 2019; Published: 1 February 2019

\begin{abstract}
Modern supply chains are vulnerable to high impact, low probability disruption risks. A supply chain usually operates in such a network of entities where the resilience of one supplier is critical to overall supply chain resilience. Therefore, resilient planning is a key strategic requirement in supplier selection decisions for a competitive supply chain. The aim of this research is to develop quantitative resilient criteria for supplier selection and order allocation in a fuzzy environment. To serve the purpose, a possibilistic fuzzy multi-objective approach was proposed and an interactive fuzzy optimization solution methodology was developed. Using the proposed approach, organizations can tradeoff between cost and resilience in supply networks. The approach is illustrated using a supply chain case from a garments manufacturing company.
\end{abstract}

Keywords: resilient supply chain; supplier selection; fuzzy optimization; disruption risks

\section{Introduction}

Outsourcing is a competitive strategy in the global supply chain. Evaluating and selecting the best set of suppliers is a challenging decision in outsourcing and it plays a significant role in supply chain performance [1,2]. Traditionally the supplier selection and order allocation decision is made based on cost and quality criteria. However, modern supply chains are more prone to unexpected High Impact Low Probability (HILP) and Low Impact High Probability (LIHP) disruption events [3]. HILP disruption events are commonly known as random disruptions risks such as man-made and natural disasters, whereas LIHP disruptions are targeted disruptions such as day-to-day operational risks. Tang and Tomlin [4] proposed six disruption sources in the supply chain and among them, supplier performance is most frequent. The role of the supplier selection decision in these supply chain risk has only been partially explored in the literature [5]. Multi-sourcing strategies and are now common to many supply chains in order to minimize the supplier's disruption risks [6]. For example, during a fire in a plant of Philips Electronics in 2010 disrupt two of its major customers: Ericsson and Nokia. Ericsson lost about a month of production and suffered $\$ 200$ million while Nokia recovered due to its multi-sourcing ability [7]. Toyota Motor Corp. lost billions of dollars in 2010 during product recall due to its part sourcing from one supplier for many car models. These examples show that multi-sourcing strategies work well. On the contrary, multi-sourcing strategies failed during some 
HILP disruption events. For example, Japan earthquake disrupted many semiconductor supply chains. Chinese Firm ZTE Corp. faced shortages of batteries and LCD screens due to all of its suppliers in the affected region. Ford Motor Co. and General Motor Co. faced shortages of auto parts and stop production due to the shutdown of two Hitachi Ltd.'s plants. These historical events suggest that the supplier selection criteria should be extended to new resilience capabilities [8]. Thus it crucial to provide a reliable level of resilience to the supply side to protect such shortages especially during HILP events [9].

Several studies have been conducted to consider resilience in the supply chain $[8,10,11]$. The concept of resilience in specific to the supplier selection problem has also been discussed by several authors [12-25]. Most of these studies focused on multiple sourcing and operational performance of suppliers. However, to the best of authors knowledge, this is the first study which focuses on supply network by considers supply density, resilience score of supplier's locations, and transit time in addition to other operational criteria. This paper aims to develop a supplier selection and order allocation model to build a resilient supply chain in response to HILP disruptions. To do so, a possibilistic multi-objective fuzzy optimization-based model with a new resilience objective is proposed which consists of supply density, resilience score, and transit time. Furthermore, the proposed model is solved using Tiwari, et al. [26] weighted additive approach and Werners [27] fuzzy and operator methods. Fuzzy based multi-objective approaches are widely used in supplier selection problem to deal with uncertain information $[28,29]$. This research answers the following questions: (i) Which supplier is selected based on the importance given to each objective? (ii) How much to purchase from each selected supplier?

The remainder of the paper is organized as follows. Section 2 provides related literature. Section 3 includes problem description and mathematical model for supplier selection and order allocation with a new resilience objective. Section 4 comprises of the proposed possibilistic fuzzy based solution methodology. Section 5 presents a numerical example to show the application of proposed supplier selection and order allocation model. Sections 6 and 7 discussed the results of the proposed mathematical model and solution methodology. Finally, Section 8 presents some conclusions and future directions drawn from the study.

\section{Literature Review}

The word resilience first coined by Holling [30] in the context of ecology. According to Holling [30], the resilience is the ability of a system to absorb changes in state variables, driving variable and parameters, and still persist. Due to the increase in complexity and uncertainty in the business environment, several studies shown interest in the concept of resilience in a managerial perspective. Hamel and Valikangas [31] defined resilience as a capacity for continuous reconstruction. Sheffi [32] defined resilience in terms of enterprise resilience as the ability of an organization to successfully confront the unforeseen. Sutcliffe and Vogus [33] stated that resilience is the (1) ability to absorb strain and improve the functionality of organization despite the presence of difficulty or (2) ability to bounce back after disturbances. More recently, Woods [34] defined resilience in simple terms as system's ability to bounce back after disruptions and to bounce forward through learning from those disruption events and increase the system's adaptive capacity for handling uncertain events.

The concept of supply chain resilience gained prominent importance during recent years in supply chain risk management research [35]. Supply chain resilience is a relatively new concept to mitigate risks that can be defined as the ability to reduce the probability of a disruption, to reduce the impact of disruption, and to reduce the recovery time to normal performance [36]. Supply chain resilience has been defined by several authors in simpler and broader terms. Most of these studies described supply chain resilience as the ability to withstand disruptions and converge to the original state or to a new desirable state. Despite the increasing number of publication in supply chain resilience area, most of the researches provided qualitative insights and there is a limited number of quantitative modelling techniques available [37]. These qualitative models used different performance measures 
for designing resilient supply chains. Priya Datta, et al. [38] developed the framework to improve operational resilience. Falasca, Zobel and Cook [36] proposed three determinants (density, complexity, and node criticality) of supply chain resilience for supply chain design. Azevedo, et al. [39] proposed GResilient index to assess supply chain resilience using the Delphi technique. Miller-Hooks, et al. [40] proposed a transportation network resilience model using stochastic programming. They presented the expected fraction of demand fulfilment after disruption as resilience metric.

Supply chain usually functions in the system of parties where the resilience of one party (e.g. a supplier) is critical for overall supply chain resilience. As discuss earlier, many major disruptions break down supply networks and it takes a long time to recover. Whereas, the probability of disruption may be reduced by developing a resilient network and it takes considerably less recovery time [41]. Suppliers constitute the most important role in the performance of the supply chain, therefore, the resilience of the supply network is expected to contribute and increase overall supply chain resilience [42]. Despite its importance, there is very limited research conducted which consider resilience of supply network. The literature on resilient supplier selection is summarized in Table 1 . Haldar, Ray, Banerjee and Ghosh [20] developed a resilient supplier selection model using AHP-QFD method to rate the suppliers. They used five resilience criteria (density, complexity, node criticality, responsiveness and re-engineering) for the supplier selection process. More recently, Haldar, Ray, Banerjee and Ghosh [21] proposed a fuzzy group decision-making approach for resilient supplier selection using triangular and trapezoidal fuzzy numbers. They considered investment, responsiveness, and capacity of holding inventory as resilient criteria. Sawik [22] proposed resilience strategies for supplier selection and order allocation problem under disruption risks. Recently, Sawik [23] proposed a stochastic mixed integer model for supplier selection and customer order scheduling using disruption risks for single and dual sourcing. Yilmaz-Börekçi, İşeri Say and Rofcanin [24] proposed a scale for measuring supplier resilience within supply networks. Mari, et al. [43] proposed a resilient and sustainable supply chain network model. They used expected disruption cost as a resilient metric. Torabi, Baghersad and Mansouri [9] developed a bi-objective stochastic model to trade-off the resilience level of the supply network and system cost. Memon, Lee and Mari [28] proposed supplier selection model using grey and uncertainty theories. Rajesh and Ravi [25] proposed a resilient supplier selection method using grey relational analysis. They consider supplier's performance, responsiveness, risk reduction, technical capabilities and sustainability as selection criteria. Sahu, Datta and Mahapatra [14] proposed fuzzy-VIKOR based supplier selection framework by combining the general selection strategy and resilience strategy. They considered investment capacity, responsiveness, and inventory capacity as resilience criteria. Hosseini and Al Khaled [13] developed a resilience score of suppliers based on eight criteria namely backup supplier contracting, surplus inventory, location separation, robustness, reliability, reorganization, rerouting, and restoration. They proposed a hybrid ensemble and AHP approach to select a suitable supplier. Pramanik, et al. [44] developed a resilient supplier selection model using AHP-TOPSIS and Sen, et al. [45] proposed g-resilient supplier selection model using dominance-based fuzzy decision making. Wang, Zhang, Chong and Wang [18] developed a resilient supplier selection model for construction supply chain by integrating building information modelling and geographical information system. Parkouhi and Ghadikolaei [12] proposed FANP and grey-VIKOR based resilient supplier selection model. They considered benefits, opportunities, costs, and risks as resilience criteria. López and Ishizaka [15] proposed a coupled method of FCM and AHP for supplier selection for a resilient supply chain. Recently, Jabbarzadeh, Fahimnia and Sabouhi [17] proposed stochastic bi-objective optimization model considering fuzzy c-means to developed sustainable supply chain network that performs resiliently. Sabouhi, Pishvaee and Jabalameli [16] presented integrated stochastic and fuzzy DEA based model for supplier selection considering resilience. They considered multi-sourcing, supplier fortification, and emergency inventory as resilience criteria. More recently, Parkouhi, et al. [46] proposed a resilient supplier selection framework using grey-DEMATEL approach. 
Table 1. The classification of literature in resilient supplier selection.

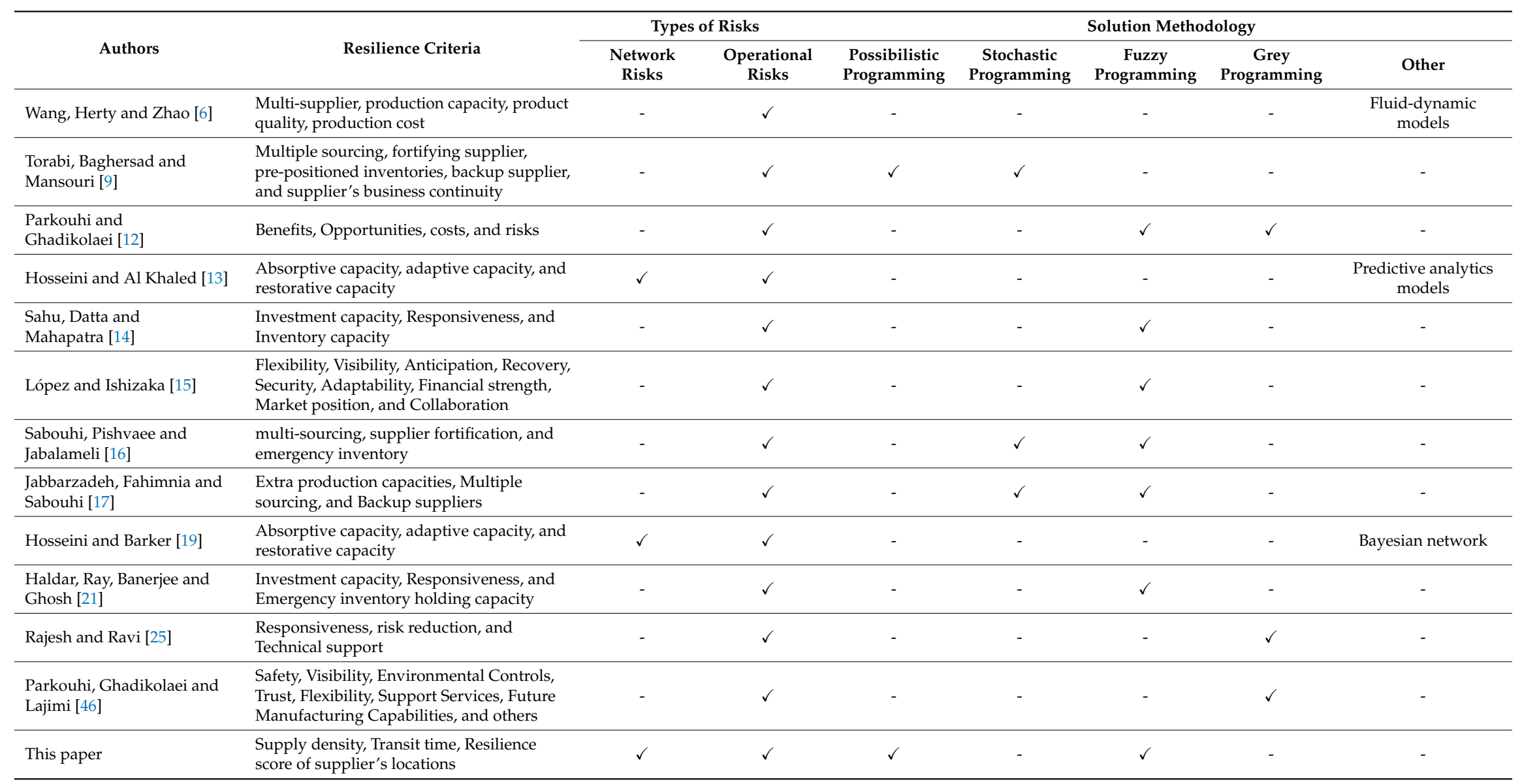


Most of the above studies considered operational risks for resilient supplier selection problem. This is the first time that a possibilistic fuzzy multi-objective model is proposed for resilient supplier selection and order allocation problem. Furthermore, for the first time in the literature supply density, resilience index score, and transit time are considered as supply selection criteria for resilient supply network.

Falasca, Zobel and Cook [36] proposed three characteristics (node criticality, supply chain complexity, and supply chain density) for building a resilient supply chain. Among them, supply chain density is the most important resilient criteria when designing supply networks under HILP disruptions. This is due to fact that denser supply networks are vulnerable to HILP disruption risks [36]. For example, 1999s Taiwan earthquake ended up having a significant effect on the entire global PC supply chain, because of the high concentration of computer component manufacturers in Hsinchu, Taiwan [47]. This example shows that the selection of a large number of suppliers from each region is a vulnerable multi-sourcing strategy, hence, this paper proposed supply density-based approach to tackle this problem. Furthermore, every country or territory has different resilient capabilities FMGlobal [48] and it affects the performance of the supply chain. Therefore, this study also proposed resilience index score-based criteria to supplier selection. The resilience index score is proposed by FMGlobal [48] is a data-driven tool to rank the countries to supply chain disruption risks. Nine key drivers of supply chain risks are considered and grouped into three categories namely: economic, risk quality, and supply chain factors. These nine drivers include local supplier quality, quality of fire risk management, GDP per capita, oil intensity, quality of hazard risk management, exposure to natural hazards, corruption control, infrastructure, and political risks [49]. Transit time is the last resilient criteria for supplier selection considered in this study. Transit time is an important indicator of supply chain flexibility [50]. Transit time reduction is one of the wildly used criteria to mitigate supply risks [51].

\section{Problem Formulation}

In this study, a garment manufacturer is assumed which want to select a suitable set of suppliers for the required material. All the model parameters are considered as fuzzy parameters. Five objectives considered in this study, namely: a cost which includes purchase and transportation costs, the rejection rate of suppliers, transit time from suppliers, supply density, and supplier resilience score based on their locations.

\subsection{Mathematical Model Notations}

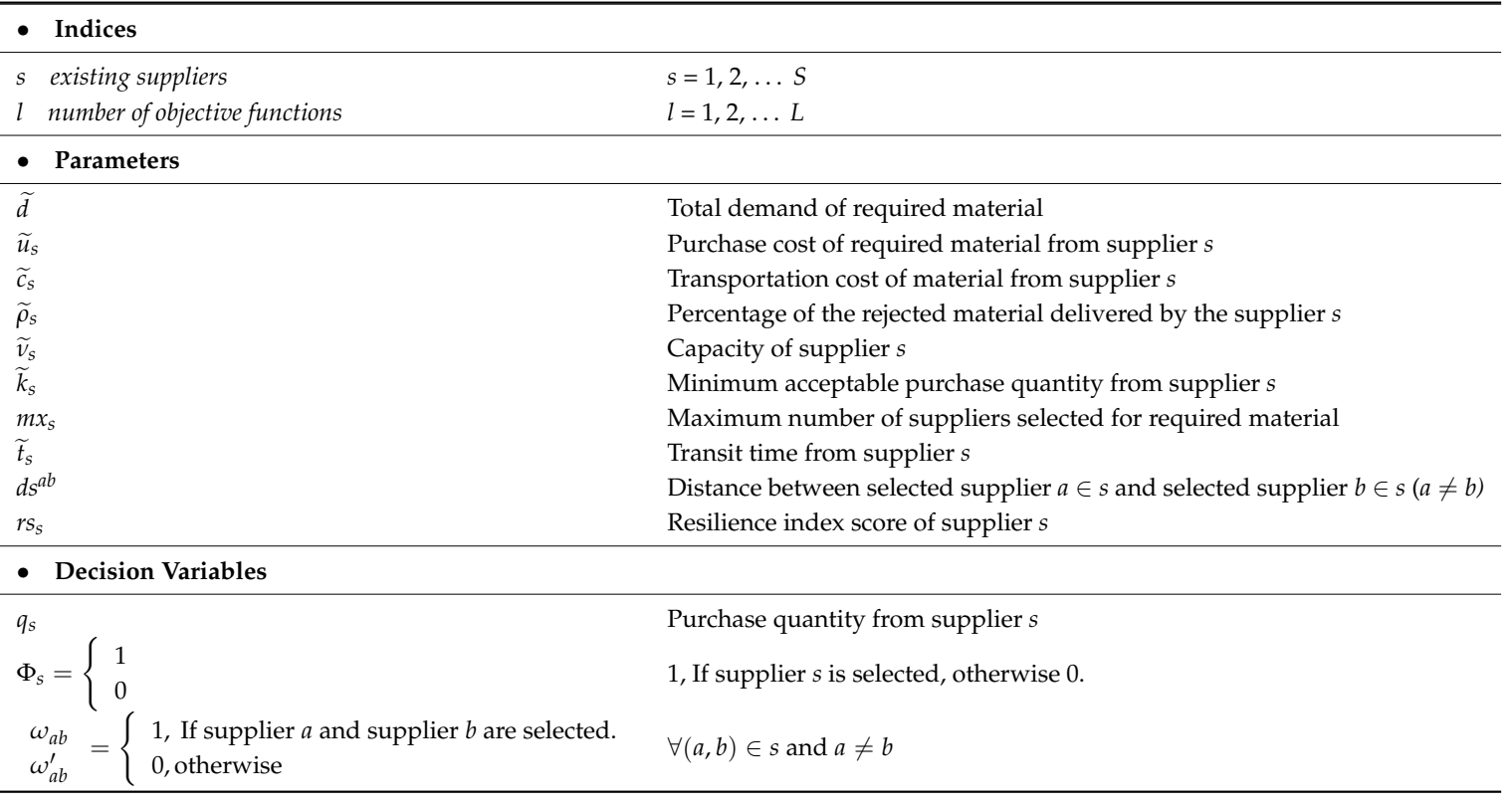




\subsection{Model Objectives}

The Equation (1) represents the objective function for the cost. It is the sum of procurement cost and transportation cost from selected suppliers. The objective function of the total rate of rejection is estimated in Equation (2). The objective function for transit time from all selected supplier is calculated as shown in Equation (3). The Equation (4) shows the supply density for all selected suppliers. Total resilience index score objective is estimated in Equation (5). Where $r s_{s}$ represents the resilience index score of supplier location obtained from FMGlobal [48].

$$
\begin{gathered}
\text { Minimize } f_{\text {cost }}=\sum_{s}\left(\widetilde{u}_{s}+\widetilde{c}_{s}\right) q_{s} \\
\text { Minimizes } f_{\text {rej }}=\sum_{s} \widetilde{\rho}_{s} q_{s} \\
\text { Minimizes } f_{\text {time }}=\sum_{s} \widetilde{t}_{s} \Phi_{s} \\
\text { Maximize } f_{\text {den }}=\frac{1}{\widetilde{d}}\left(\begin{array}{c}
\sum_{a \in s} d s^{a b} \Phi_{s} \\
a \neq b \\
a \neq b \\
\text { Maximize } f_{\text {res }}=\sum_{s} \frac{r s_{s} q_{s}}{\widetilde{d}}
\end{array}\right)
\end{gathered}
$$

\subsection{Model Constraints}

Constraint (6) ensures that total procured material should satisfy its demand.

$$
\sum_{s} q_{s}=\widetilde{d}
$$

Constraint (7) is capacity restrictions on the supplier. Also, it controls the flow between the supplier and the buyer through a binary variable. Constraint (8) ensures that purchase quantity from the selected supplier will be more than its acceptable order quantity limit. Constraint (9) restricts the maximum allowable supplier to be selected for the required material.

$$
\begin{gathered}
q_{s} \leq \widetilde{v}_{s} \Phi_{s} \\
q_{s} \geq \widetilde{k}_{s} \Phi_{s} \\
\sum_{s} \Phi_{s} \leq m x_{s}
\end{gathered}
$$

Constraints (10) and (11) determine the intra-stage flow between suppliers and buyer. If buyer received material from both supplier $a$ and supplier $b$ then $\omega_{a b}=\Phi_{a \epsilon s}=\Phi_{b e s}=1$ and $\omega_{a b}^{\prime}=0$. On the contrary, if buyer not received material from both supplier $a$ and supplier $b$ then $\omega_{a b}^{\prime}=1, \omega_{a b}=0$ and $\Phi_{a \epsilon s} \neq \Phi_{b e s}$.

$$
\begin{gathered}
2 \omega_{a b}+\omega_{a b}^{\prime}=\Phi_{a \in s}+\Phi_{b \in s} \\
\forall(a, b) \in s \text {, and } a \neq b \\
\omega_{a b}+\omega_{a b}^{\prime} \leq 1 \\
\forall(a, b) \in s, \text { and } a \neq b
\end{gathered}
$$




\section{Fuzzy Based Solution Methodology}

Fuzzy based programming methods are highly used for multi-objective optimization because of their capability in measuring and adjusting the decision maker's satisfaction level of each objective function explicitly. In addition, the fuzzy theory is helpful to tackle the uncertain parameters related to supply chain optimization problem [52]. The main advantage of interactive fuzzy based approaches is that decision maker can efficiently achieve his/her preferences by controlling the search direction. The proposed solution methodology consists of the following steps.

\section{Step 1: Convert uncertain mathematical model to equivalent auxiliary crisp}

The proposed mathematical model is converted to an equivalent auxiliary crisp model. In this study, Jiménez, Arenas, Bilbao and Rodrı [51] approach is used which is based on an expected interval (EI) and expected value (EV) of fuzzy numbers. According to Jiménez, Arenas, Bilbao and Rodr1 [51], the EI and EV of triangular fuzzy number (TFN) can be defined as in equation (12) and (13) respectively. Where $\vartheta^{\text {pes }}$ is the pessimistic value, $\vartheta^{\text {mos }}$ is the most likely value, and $\vartheta^{\text {opt }}$ is the optimimum value of triangular fuzzy number $(\vartheta)$. This research considered TFN because it is frequently used for a practical purpose [53].

$$
\begin{gathered}
E I(\widetilde{\vartheta})=\left[E_{1}^{\vartheta}, E_{2}^{\vartheta}\right]=\left[\int_{0}^{1} f_{\vartheta}^{-1}(x) d x, \int_{0}^{1} g_{\vartheta}^{-1}(x) d x,\right]=\left[\frac{1}{2}\left(\vartheta^{p e s}+\vartheta^{m o s}\right), \frac{1}{2}\left(\vartheta^{m o s}+\vartheta^{o p t}\right)\right] \\
E V(\widetilde{\vartheta})=\frac{E_{1}^{\vartheta}+E_{1}^{\vartheta}}{2}=\frac{\vartheta^{\text {pes }}+2 \vartheta^{m o s}+\vartheta^{o p t}}{4}
\end{gathered}
$$

Using the above Equations (12) and (13), the equivalent auxiliary crisp model can be formulated as follows.

$$
\begin{aligned}
& \text { Minimize } f_{\text {cost }}=\sum_{s}\left(\frac{u_{s}^{p e s}+2 u_{s}^{\text {mos }}+u_{s}^{o p t}+c_{s}^{p e s}+2 c_{s}^{m o s}+c_{s}^{o p t}}{4}\right) q_{s} \\
& \text { Minimizes } f_{r e j}=\sum_{s}\left(\frac{\rho_{s}^{p e s}+2 \rho_{s}^{m o s}+\rho_{s}^{o p t}}{4}\right) q_{s} \\
& \text { Minimizes } f_{\text {time }}=\sum_{s}\left(\frac{t_{s}^{\text {pes }}+2 t_{s}^{\text {mos }}+t_{s}^{o p t}}{4}\right) \Phi_{s} \\
& \text { Maximize } f_{\text {den }}=\frac{1}{\frac{d^{p e s}+2 d^{m o s}+d^{o p t}}{4}}\left(\sum_{\substack{a \in s \\
\sum_{b \in s}}} d s^{a b} \Phi_{s}\right) \\
& \text { Maximize } f_{\text {res }}=\sum_{s} \frac{r s_{s} q_{s}}{\frac{d^{p e s}+2 d^{m o s}+d^{o p t}}{4}}
\end{aligned}
$$

Subject to

$$
\begin{aligned}
& \sum_{s} q_{s} \geq\left[\frac{\alpha}{2}\left(\frac{d^{m o s}+d^{o p t}}{2}\right)+\left(1-\frac{\alpha}{2}\right)\left(\frac{d^{p e s}+d^{m o s}}{2}\right)\right] \\
& \sum_{s} q_{s} \leq\left[\frac{\alpha}{2}\left(\frac{d^{p e s}+d^{m o s}}{2}\right)+\left(1-\frac{\alpha}{2}\right)\left(\frac{d^{m o s}+d^{o p t}}{2}\right)\right] \\
& q_{s} \leq \Phi_{s}\left[\alpha\left(\frac{v_{s}^{p e s}+v_{s}^{m o s}}{2}\right)+(1-\alpha)\left(\frac{v_{s}^{m o s}+v_{s}^{o p t}}{2}\right)\right]
\end{aligned}
$$




$$
\begin{gathered}
q_{s} \geq \Phi_{s}\left[\alpha\left(\frac{k^{m o s}+k^{o p t}}{2}\right)+(1-\alpha)\left(\frac{k^{p e s}+k^{m o s}}{2}\right)\right] \\
\sum_{s} \Phi_{s} \leq m x_{s} \\
2 \omega_{a b}+\omega_{a b}^{\prime}=\Phi_{a \in s}+\Phi_{b \in s} \\
\omega_{a b}+\omega_{a b}^{\prime} \leq 1
\end{gathered}
$$

\section{Step 2: Determine $\alpha$ - extreme solutions}

To estimate the upper $(\alpha-\mathrm{UB})$ and lower $(\alpha-\mathrm{LB})$ bounds to each objective, the crisp model developed in Step 1 is solved for each objective along with its constraint.

\section{Step 3: Determine fuzzy membership function}

Develop the fuzzy membership function for each objective using lower $(\alpha-\mathrm{LB})$ and upper $(\alpha$-UB) bound values. The linear memberships for fuzzy goals are given as follows. It is assumed that membership functions are linear based on preferences and satisfaction level.

$$
\begin{gathered}
\mu_{\text {cost }}(x)= \begin{cases}1, & f_{\text {cost }}(x) \leq f_{\text {cost }}^{\alpha-L B} \\
\frac{f_{\text {cost }}^{\alpha-U B}-f_{\text {cost }}(x)}{f_{\text {cost }}^{\alpha-U B}-f_{\text {cost }}^{\alpha-L B},} & f_{\text {cost }}^{\alpha-L B}<f_{\text {cost }}(x) \leq f_{\text {cost }}^{\alpha-U B} \\
0, & f_{\text {cost }}(x) \geq f_{\text {cost }}^{\alpha-U B}\end{cases} \\
\mu_{\text {rej }}(x)= \begin{cases}1, & f_{\text {rej }}(x) \leq f_{\text {rej }}^{\alpha-L B} \\
\frac{f_{\text {rej }}^{\alpha-U B}-f_{\text {rej }}(x)}{f_{\text {rej }}^{\alpha-U B}-f_{\text {rej }}^{\alpha-L B},} & f_{\text {rej }}^{\alpha-L B} \leq f_{\text {rej }}(x) \leq f_{\text {rej }}^{\alpha-U B} \\
0, & f_{\text {rej }}(x) \geq f_{\text {rej }}^{\alpha-U B}\end{cases} \\
\mu_{\text {time }}(x)= \begin{cases}1, & f_{\text {time }}(x) \leq f_{\text {time }}^{\alpha-L B} \\
\frac{f_{\text {time }}^{\alpha-U B}-f_{\text {time }}(x),}{f_{\text {time }}^{\alpha-U B}-f_{\text {time }}^{\alpha-L B},} & f_{\text {time }}^{\alpha-L B} \leq f_{\text {time }}(x) \leq f_{\text {time }}^{\alpha-U B} \\
0, & f_{\text {time }}(x) \geq f_{\text {time }}^{\alpha-U B}\end{cases} \\
\mu_{\text {den }}(x)= \begin{cases}1, & f_{\text {den }}(x) \geq f_{\text {den }}^{\alpha-U B} \\
\frac{f_{\text {den }}(x)-f_{\text {den }}^{\alpha-L B}}{f_{\text {den }}^{\alpha-U B}-f_{\text {den }}^{\alpha-L B},} & f_{\text {den }}^{\alpha-U B} \leq f_{\text {den }}(x) \leq f_{\text {den }}^{\alpha-L B} \\
0, & f_{\text {den }}(x) \leq f_{\text {den }}^{\alpha-L B}\end{cases} \\
\mu_{\text {res }}(x)= \begin{cases}1, & f_{\text {res }}(x) \geq f_{\text {res }}^{\alpha-U B} \\
\frac{f_{\text {res }}(x)-f_{\text {res }}^{\alpha-L B}}{f_{\text {res }}^{\alpha-U B}-f_{\text {res }}^{\alpha-L B},} & f_{\text {res }}^{\alpha-U B} \leq f_{\text {res }}(x) \leq f_{\text {res }}^{\alpha-L B} \\
0, & f_{\text {res }}(x) \leq f_{\text {res }}^{\alpha-L B}\end{cases}
\end{gathered}
$$

where $f_{l}^{\alpha-L B}$ is a minimum value of $f_{l}(x)$ and $f_{l}^{\alpha-U B}$ is a maximum value of $f_{l}(x)$ with predefined $\alpha$. These values the $l^{\text {th }}$ objective depends on its nature. $f_{l}^{\alpha-L B}$ are set as the aspiration level of cost, rejection rate, and transit time objective. Whereas $f_{l}^{\alpha-U B}$ are set as the aspiration level of supply density and resilience index.

\section{Step 4: Convert the multi-objective model into a single objective}

The proposed model is converted into the single objective in this stage. In this paper, two most popular fuzzy based approaches i.e., Tiwari, Dharmar and Rao [26] weighted additive approach and Werners [27] fuzzy and operator are implemented. 
The weighted additive approach allows the buyer to assign different weights to objectives in the simple additive fuzzy achievement function. Mathematical formulation of the weighted additive method is as follows.

$$
\left.\begin{array}{ll}
\operatorname{maximize} & \sum_{l} w_{l} \mu_{z l}(x) \\
\text { subject to } & \mu_{z l}(x) \in[0,1], \quad \forall l \\
& x \geq 0
\end{array}\right\}
$$

where $w_{l}$ represents the weight of $i^{\text {th }}$ objective. Selection of weights are subjected choice of decision makers and some good techniques can be used to determine the weights such as FAHP and structural equation modelling.

Werners' fuzzy and operator method are widely used interactive method. The advantage of this method is that it is positively related to the compensation rate due to its strong monotonicity. Additionally, it is easy to handle and has generated reasonable consistent results in applications [54]. By adopting the Werner's' method following a single objective model can be formed.

$$
\left.\begin{array}{ll}
\text { maximize } & \gamma \zeta_{0}+(1-\gamma) \sum_{l} \zeta_{1} \\
\text { subject to } & \mu_{1}(x) \geq \zeta_{0}+\zeta_{1}, \quad \forall l \\
& \zeta_{0}, \zeta_{1}, \gamma \in[0,1]
\end{array}\right\}
$$

where, $\zeta_{1}$ is the difference between satisfaction level of objectives their minimum satisfaction level $\zeta_{0}$, That is, $\zeta_{1}=\mu_{1}-\zeta_{0}$. $\gamma$ denotes the coefficient of compensation.

\section{Step 5: Determine the solution method parameter}

Determine the values of the relative importance of objectives $\left(w_{l}\right)$ and coefficient of compensation $(\gamma)$ to solve the mathematical model using both weighted additive approach and Werners' fuzzy and operator methods.

\section{Step 6: Solve the model}

In the last step, solve the model by using parameters of the mathematical model and solution methods. This process continues by varying the solution method parameters (i.e., $\gamma$ and $w_{l}$ ) until decision makers are satisfied with the final solution. If decision makers want to modify the value of $\alpha$, then restart the process from step 2.

\section{An Illustration}

The effectiveness of the proposed resilient supplier selection model and solution methodology is demonstrated in this section. The data relates to a realistic situation of a garment manufacturing sector as shown in Figure 1. The adopted situation can easily be extended to any other industry. Initially, the data are estimated as most likely values, these most likely values of the fuzzy parameter $\left(f z^{m o s}\right)$ are estimated using available information or hypothetically set based on realistic assumption. The pessimistic and optimistic values are estimated using $f z^{\text {pes }}=\left(1-\eta_{1}\right) f z^{\text {mos }}$ and, where two random numbers $\eta_{1}$ and $\eta_{2}$ are assumed between 0.2 and 0.8 to estimate. Table 2 shows the data set of unit purchase cost, transportation cost, rejection rate, capacity, and resilience index score of potential suppliers. The unit purchase costs from each supplier are hypothetical set based on labour cost, land value, resource availability at supplier locations. Transportation cost and transit time (see Table 3) from each supplier to manufacturer are estimated from sea rates (https:/ / www.searates.com/). The resilience index score of each supplier is estimated from FM, Global resilience index data-driven tool (https:/ / www.fmglobal.com/) based on the location of suppliers. The distance (as the crow flies) between suppliers (see Table 4) are calculated using the Google maps (https:/ / www.google.com/ maps). The demand for raw materials is assumed as most likely 8000 units, minimum acceptable order quantity is assumed as 1000 units, and maximum three suppliers can be selected for required material. 


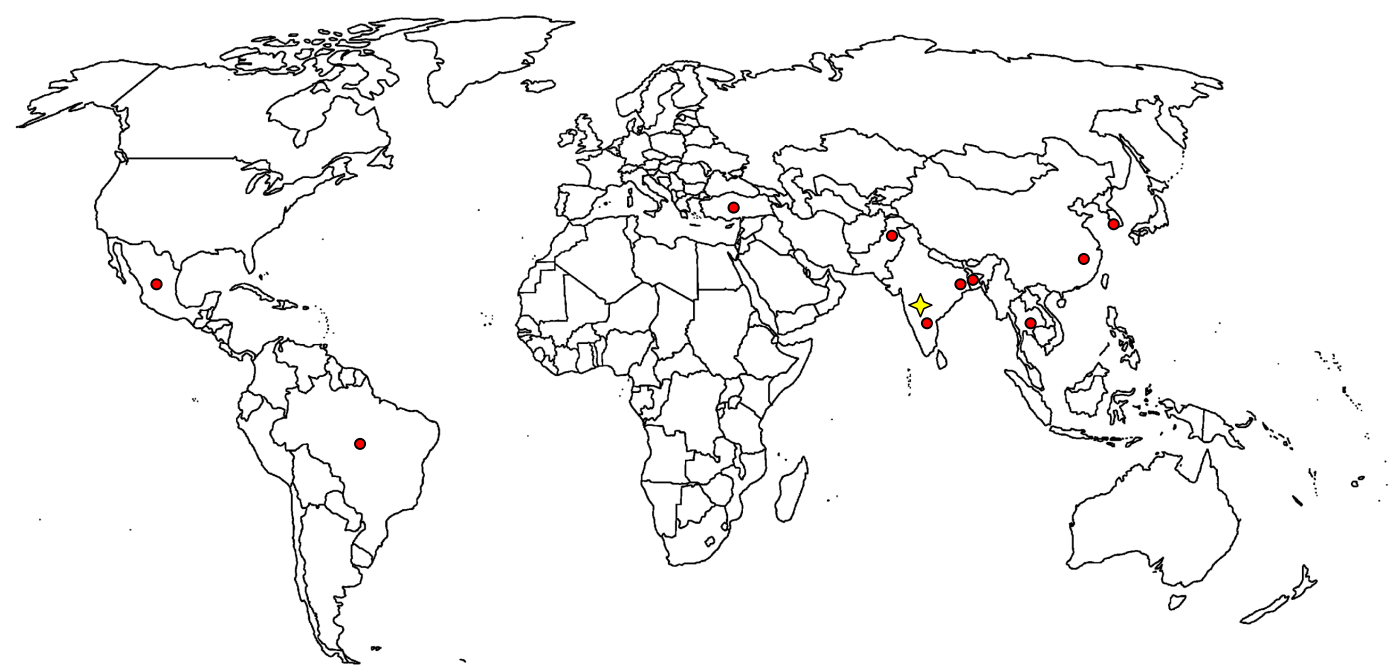

- Potential supplier location $\&$ Existing Manufacturer

Figure 1. Supply network of the problem under consideration.

Table 2. Model input data.

\begin{tabular}{|c|c|c|c|c|c|}
\hline $\begin{array}{l}\text { Potential } \\
\text { Supplier } \\
\text { Location }\end{array}$ & $\begin{array}{l}\text { Purchase Cost } \\
\text { of Material } \\
\text { (\$/unit) }\end{array}$ & $\begin{array}{l}\text { Transportation } \\
\text { Cost of Material } \\
\text { (\$/unit) }\end{array}$ & $\begin{array}{c}\text { Percentage of } \\
\text { the Rejected } \\
\text { Material }\end{array}$ & $\begin{array}{l}\text { Capacity of } \\
\text { Suppliers } \\
\text { (1000 units) }\end{array}$ & $\begin{array}{c}\text { Resilience } \\
\text { Score }\end{array}$ \\
\hline Korea & $(6,8,10)$ & $(0.08,0.13,0.21)$ & $(0.01,0.01,0.02)$ & $(3.08,5,8.08)$ & 42.1 \\
\hline China & $(1,2,4)$ & $(0.11,0.19,0.30)$ & $(0.04,0.06,0.10)$ & $(3.7,6,9.7)$ & 45.3 \\
\hline Thailand & $(4,6,8)$ & $(0.05,0.09,0.14)$ & $(0.02,0.03,0.05)$ & $(3.08,5,8.08)$ & 39 \\
\hline Bangladesh & $(1,3,5)$ & $(0.11,0.17,0.28)$ & $(0.02,0.03,0.05)$ & $(3.7,6,9.7)$ & 29 \\
\hline India-(Calcutta) & $(3,5,7)$ & $(0.10,0.16,0.26)$ & $(0.01,0.02,0.03)$ & $(2.46,4,6.46)$ & 27.1 \\
\hline India-(Hyderabad) & $(3,4,5)$ & $(0.01,0.02,0.03)$ & $(0.01,0.02,0.03)$ & $(4.62,7.5,12.12)$ & 27.1 \\
\hline Pakistan & $(3,5,7)$ & $(0.06,0.10,0.16)$ & $(0.01,0.02,0.03)$ & $(3.08,5,8.08)$ & 22.2 \\
\hline Turkey & $(8,10,12)$ & $(0.08,0.12,0.20)$ & $(0.01,0.01,0.02)$ & $(3.08,5,8.08)$ & 38.4 \\
\hline Brazil & $(6,8,10)$ & $(0.09,0.14,0.22)$ & $(0.02,0.04,0.06)$ & $(3.7,6,9.7)$ & 47.8 \\
\hline Mexico & $(7,9,11)$ & $(0.11,0.17,0.28)$ & $(0.02,0.03,0.05)$ & $(4.31,7,11.31)$ & 44.8 \\
\hline
\end{tabular}

Table 3. Transit time from suppliers.

\begin{tabular}{cc}
\hline Supplier Location & Transit Time (days) \\
\hline Korea & $(7.39,12,19.39)$ \\
China & $(9.24,15,24.24)$ \\
Thailand & $(1.23,2,3.23)$ \\
Bangladesh & $(1.85,3,4.85)$ \\
India-(Calcutta) & $(1.23,2,3.23)$ \\
India-(Hyderabad) & $(0.62,1,1.62)$ \\
Pakistan & $(3.08,5,8.08)$ \\
Turkey & $(8.01,13,21.01)$ \\
Brazil & $(14.78,24,38.78)$ \\
Mexico & $(19.71,32,51.71)$ \\
\hline
\end{tabular}

Table 4. The distance between suppliers (kilometers).

\begin{tabular}{|c|c|c|c|c|c|c|c|c|c|c|}
\hline $\begin{array}{l}\text { Suppliers' } \\
\text { location. }\end{array}$ & Korea & China & Thailand & Bangladesh & $\begin{array}{c}\text { India } \\
\text { (Calcutta) }\end{array}$ & $\begin{array}{c}\text { India } \\
\text { (Hyderabad) }\end{array}$ & Pakistan & Turkey & Brazil & Mexico \\
\hline Korea & N/A & 1028.16 & 3723.83 & 3783.61 & 4037.39 & 5212.7 & 5768.78 & 7641.12 & $16,739.92$ & $12,029.52$ \\
\hline China & 1028.16 & N/A & 2743.18 & 3059.41 & 3304.68 & 4478.2 & 5273.64 & 7587.05 & $17,589.43$ & $13,051.91$ \\
\hline Thailand & 3723.83 & 2743.18 & $\mathrm{~N} / \mathrm{A}$ & 1526.77 & 1616.16 & 2388.26 & 3709.84 & 6926.22 & $17,348.59$ & $15,721.92$ \\
\hline Bangladesh & 3783.61 & 3059.41 & 1526.77 & N/A & 250.06 & 1432.18 & 2374.24 & 5408.55 & $16,067.89$ & $15,092.77$ \\
\hline India (Calcutta) & 4037.39 & 3304.68 & 1616.16 & 250.06 & N/A & 1180.87 & 2186.91 & 5327.76 & $15,902.02$ & $15,299.76$ \\
\hline India (Hyderabad) & 5212.7 & 4478.2 & 2388.26 & 1432.18 & 1180.87 & $\mathrm{~N} / \mathrm{A}$ & 1461.88 & 4788.23 & $14,979.22$ & $15,878.77$ \\
\hline Pakistan & 5768.78 & 5273.64 & 3709.84 & 2374.24 & 2186.91 & 1461.88 & N/A & 3334.57 & $13,710.04$ & $14,838.79$ \\
\hline Turkey & 7641.12 & 7587.05 & 6926.22 & 5408.55 & 5327.76 & 4788.23 & 3334.57 & N/A & $10,723.38$ & $11,983.21$ \\
\hline Brazil & $16,739.92$ & $17,589.43$ & $17,348.59$ & $16,067.89$ & $15,902.02$ & $14,979.22$ & $13,710.04$ & $10,723.38$ & N/A & 5692.39 \\
\hline Mexico & $12,029.52$ & $13,051.91$ & $15,721.92$ & $15,092.77$ & $15,299.76$ & 15878.77 & $14,838.79$ & $11,983.21$ & 5692.39 & N/A \\
\hline
\end{tabular}




\section{Model Solution and Result Analysis}

The proposed fuzzy multi-objective model is solved in Lingo 14.0. Lingo optimization software has been widely used in supply chain optimization problems [55,56]. According to the steps of the proposed methodology, the payoff values are estimated by solving the single objective model. Table 5 shows payoff values estimated from the single objective model. The aspiration level of cost, rejection, transit time, supply density, and resilience score are estimated as $\$ 22,514.93,0.025,3.17$ days, 0.286 , and 47.89 respectively. Once the payoff values are estimated, the fuzzy membership functions of objectives are estimated as shown below.

$$
\begin{gathered}
\mu_{\text {cost }}\left(q_{s}\right)=\left\{\begin{array}{l}
1, f_{\text {cost }}\left(q_{s}\right) \leq 22514.93 \\
75796.12-f_{\text {cost }}\left(q_{s}\right) \\
75796.12-22514.93 \\
0, f_{\text {cost }}\left(q_{s}\right) \geq 75796.12
\end{array}\right. \\
\mu_{\text {rej }}\left(q_{s}\right)=\left\{\begin{array}{l}
1, f_{\text {rej }}\left(q_{s}\right) \leq 0.025 \\
\frac{0.10-f_{\text {rej }}\left(q_{s}\right)}{0.10-0.025}, 0.025 \leq f_{\text {rest }}\left(q_{s}\right) \leq 75796.12 \\
0, f_{\text {rej }}\left(q_{s}\right) \geq 0.10
\end{array}\right. \\
\mu_{\text {time }}\left(q_{s}\right)=\left\{\begin{array}{l}
1, f_{\text {time }}\left(q_{s}\right) \leq 3.17 \\
\frac{61.11-f_{\text {time }}\left(q_{s}\right)}{61.11-3.17}, 3.17 \leq f_{\text {time }}\left(q_{s}\right) \leq 61.11 \\
0, f_{\text {time }}\left(q_{s}\right) \geq 61.11
\end{array}\right. \\
\mu_{\text {den }}\left(q_{s}\right)=\left\{\begin{array}{l}
1, f_{\text {den }}\left(q_{s}\right) \geq 0.28 \\
\frac{f_{\text {den }}\left(q_{s}\right)-0.017}{0.28-0.017}, 0.017 \leq f_{\text {den }}\left(q_{s}\right) \leq 0.28 \\
0, f_{\text {den }}\left(q_{s}\right) \leq 0.017
\end{array}\right. \\
\mu_{\text {res }}\left(q_{s}\right)=\left\{\begin{array}{l}
1, f_{\text {res }}\left(q_{s}\right) \geq 47.89 \\
\frac{f_{\text {res }}\left(q_{s}\right)-29.79}{47.89-29.79}, 29.79 \leq f_{\text {res }}\left(q_{s}\right) \leq 47.89 \\
0, f_{\text {res }}\left(q_{s}\right) \leq 29.79
\end{array}\right.
\end{gathered}
$$

Table 5. Payoff values.

\begin{tabular}{lccccc}
\hline \multicolumn{1}{c}{ Objective } & Cost $\mathbf{( \$ )}$ & $\begin{array}{c}\text { Rejection } \\
\mathbf{( \% )}\end{array}$ & $\begin{array}{c}\text { Transit Time } \\
\text { (days) }\end{array}$ & $\begin{array}{c}\text { Supply } \\
\text { Density }\end{array}$ & $\begin{array}{c}\text { Resilience } \\
\text { Score }\end{array}$ \\
\hline Minimize Cost & $22,514.93$ & 0.097 & 19.04 & 0.022 & 38.2 \\
Minimize Rejection & $75,796.12$ & 0.025 & 26.45 & 0.056 & 39.22 \\
Minimize Transit time & $38,143.47$ & 0.052 & 3.17 & 0.017 & 29.79 \\
Maximize Supply density & $70,159.31$ & 0.1 & 61.11 & 0.286 & 43.41 \\
Maximize Resilience score & $50,560.14$ & 0.1 & 41 & 0.12 & 47.89 \\
\hline
\end{tabular}

The proposed mathematical model is solved using both methods, that is, a weighted additive approach and Werners' 'fuzzy and' operator methods. A solution of illustrated case example using both methods is shown in Table 6 . The result shows that both methods produce a comprehensive optimal solution. However, the weighted additive approach considers the importance of objectives based on the weight given to each objective. For example, when more importance is given to resilience score (i.e., $w_{5}=0.3$ ), it results in $78.6 \%$ achievement of aspiration level. On the other hand, when all objectives and equal importance (Werners' method) than resilience score is given, the objective results in 34\% achievement of aspiration level. Comparative analysis of both methods is shown in Figure 2. 
Table 6. Solution of a case example.

\begin{tabular}{ccccc}
\hline \multirow{2}{*}{ Model Objectives } & \multicolumn{2}{c}{ Weighted Additive Approach ${ }^{\mathbf{a}}$} & \multicolumn{2}{c}{ Werners' 'Fuzzy and' Operator $^{\mathbf{b}}$} \\
\cline { 2 - 5 } & $\boldsymbol{\mu}_{\boldsymbol{l}}(\boldsymbol{x})$ & $f_{l}(\boldsymbol{x})$ & $\boldsymbol{\mu}_{\boldsymbol{l}}(\boldsymbol{x})$ & $\boldsymbol{f}_{\boldsymbol{l}}(\boldsymbol{x})$ \\
\hline Cost & 0.346 & $78,238.03$ & 0.195 & $65,374.99$ \\
Rejection & 0.051 & 0.12 & 0.366 & 0.072 \\
Transit time & 0.457 & 42.0 & 0.383 & 38.89 \\
Supply density & 0.975 & 0.27 & 0.972 & 0.272 \\
Resilience score & 0.786 & 75.5 & 0.803 & 44.33 \\
\hline
\end{tabular}

$\alpha=0.9,{ }^{\mathrm{a}} w_{1}=0.2, w_{2}=0.1, w_{3}=0.2, w_{4}=0.2, w_{5}=0.3,{ }^{\mathrm{b}} \gamma=0.7$.

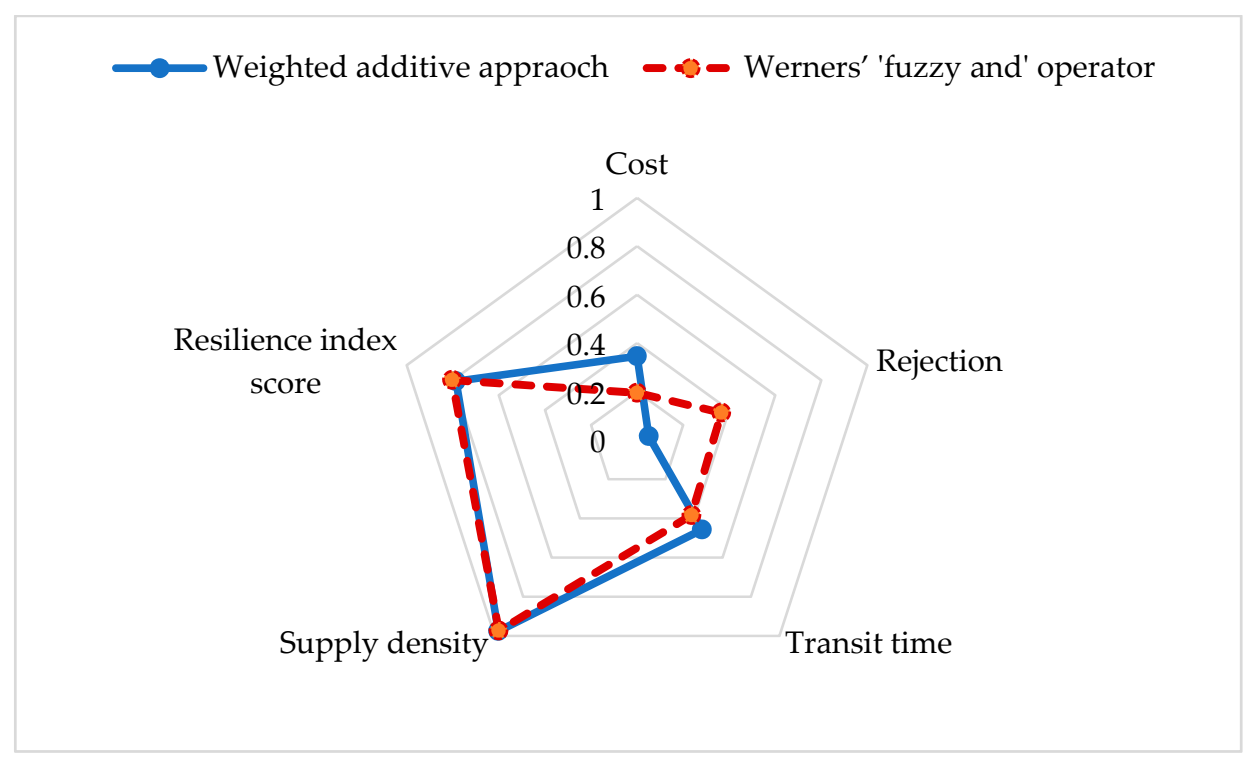

Figure 2. Achievement levels of objectives.

\section{Sensitivity Analysis}

Sensitivity analysis of both methods is carried out by varying methodology parameters (i.e., $\alpha$, $\gamma$ and $w_{l}$ ) as discussed in the final step of the proposed solution methodology. Tables 7 and 8 show the analysis result of the weighted additive approach and Werners' 'fuzzy and' operator method, respectively. Two cases are solved with the weighted additive approach: (1) more importance is given to resilience objective and (2) more importance given to cost objective.

The result shows that there is a tradeoff in economic objective and resilience objective. Hence, it can be said that the increase is supply chain resilience will tend to increase the total cost of the supply network. This is possible because economic supply networks are more dense networks in order to minimize transportation cost, hence any HILP disruption event such as earthquake or tsunami may disrupt more than one supplier. Therefore, it is suggested that companies should avoid denser supply networks to minimize risks from high impact low probability disruption event. Analysis result shows that $92 \%$ achievement of cost aspiration level will bring achievement of about only $6.1 \%$ supply density and $49.8 \%$ resilience index score aspiration levels respectively. On the other hand, $18.4 \%$ achievement of cost aspiration level will bring achievement of about $97 \%$ supply density and $88.1 \%$ resilience index score respectively. 
Table 7. Sensitivity analysis of the weighted additive approach.

\begin{tabular}{|c|c|c|c|c|c|c|c|c|c|c|c|}
\hline Alpha & $\begin{array}{l}\text { Objective } \\
\text { Weights }\end{array}$ & $\mu_{\text {cost }}$ & $\mu_{r e j}$ & $\mu_{\text {time }}$ & $\mu_{d e n}$ & $\mu_{\text {res }}$ & $f_{\text {cost }}$ & $f_{r e j}$ & $f_{\text {time }}$ & $f_{d e n}$ & $f_{\text {res }}$ \\
\hline \multirow[t]{2}{*}{0.9} & $\begin{array}{c}w_{1}=0.2, w_{2}=0.1 \\
w_{3}=0.2, w_{4}=0.2 \\
w_{5}=0.3\end{array}$ & 0.184 & 0.200 & 0.365 & 0.97 & 0.881 & $65,941.28$ & 0.085 & 39.9 & 0.27 & 45.7 \\
\hline & $\begin{array}{c}w_{1}=0.3, w_{2}=0.2 \\
w_{3}=0.2, w_{4}=0.1 \\
w_{5}=0.2\end{array}$ & 0.920 & 0.200 & 0.762 & 0.061 & 0.498 & $26,730.90$ & 0.085 & 16.9 & 0.03 & 38.8 \\
\hline \multirow[t]{2}{*}{0.6} & $\begin{array}{c}w_{1}=0.2, w_{2}=0.1 \\
w_{3}=0.2, w_{4}=0.2 \\
w_{5}=0.3\end{array}$ & 0.111 & 0.100 & 0.566 & 0.910 & 0.935 & $66,577.34$ & 0.092 & 28.3 & 0.25 & 47.4 \\
\hline & $\begin{array}{c}w_{1}=0.3, w_{2}=0.2 \\
w_{3}=0.2, w_{4}=0.1 \\
w_{5}=0.2\end{array}$ & 0.851 & 0.200 & 0.762 & 0.061 & 0.634 & $27,727.65$ & 0.085 & 16.9 & 0.03 & 42.6 \\
\hline
\end{tabular}

Table 8. Sensitivity analysis of Werners' 'fuzzy and' operator.

\begin{tabular}{cccccccccccc}
\hline$\alpha$ & $\gamma$ & $\mu_{\text {cost }}$ & $\mu_{\text {rej }}$ & $\mu_{\text {time }}$ & $\mu_{\text {den }}$ & $\mu_{\text {res }}$ & $f_{\text {cost }}$ & $f_{\text {rej }}$ & $f_{\text {time }}$ & $f_{\text {den }}$ & $f_{\text {res }}$ \\
\hline \multirow{4}{*}{0.6} & $0.0-0.8$ & 0.107 & 0.366 & 0.383 & 0.972 & 0.793 & $66,774.85$ & 02.072 & 38.8 & 0.27 & 46.4 \\
& 0.9 & 0.366 & 0.366 & 0.383 & 0.972 & 0.451 & $53,167.88$ & 0.072 & 38.89 & 0.27 & 38.3 \\
& 1.0 & 0.407 & 0.566 & 0.543 & 0.407 & 0.406 & $51,054.51$ & 0.057 & 29.62 & 0.12 & 37.3 \\
\multirow{2}{*}{0.9} & $0.0-0.8$ & 0.195 & 0.366 & 0.383 & 0.972 & 0.803 & $65,374.99$ & 0.072 & 38.89 & 0.27 & 44.33 \\
& 0.9 & 0.366 & 0.366 & 0.383 & 0.972 & 0.541 & $56,259.06$ & 0.072 & 38.89 & 0.27 & 39.59 \\
& 1.0 & 0.392 & 0.566 & 0.543 & 0.407 & 0.392 & $54,899.34$ & 0.057 & 29.6 & 0.12 & 36.88 \\
\hline
\end{tabular}

Assume that decision makers required balance results and choose the best outcome at $\alpha=0.9$, and $\gamma=1.0$ (highlighted row in Table 8). Hence, the final decision of the illustrated example is shown in Figure 3. The optimal quantity of material purchase from suppliers are $q$ (Korea) $=3751$ units, $q($ Bangladesh $)=3655$ units, and $q$ (Turkey $)=1258$ units.

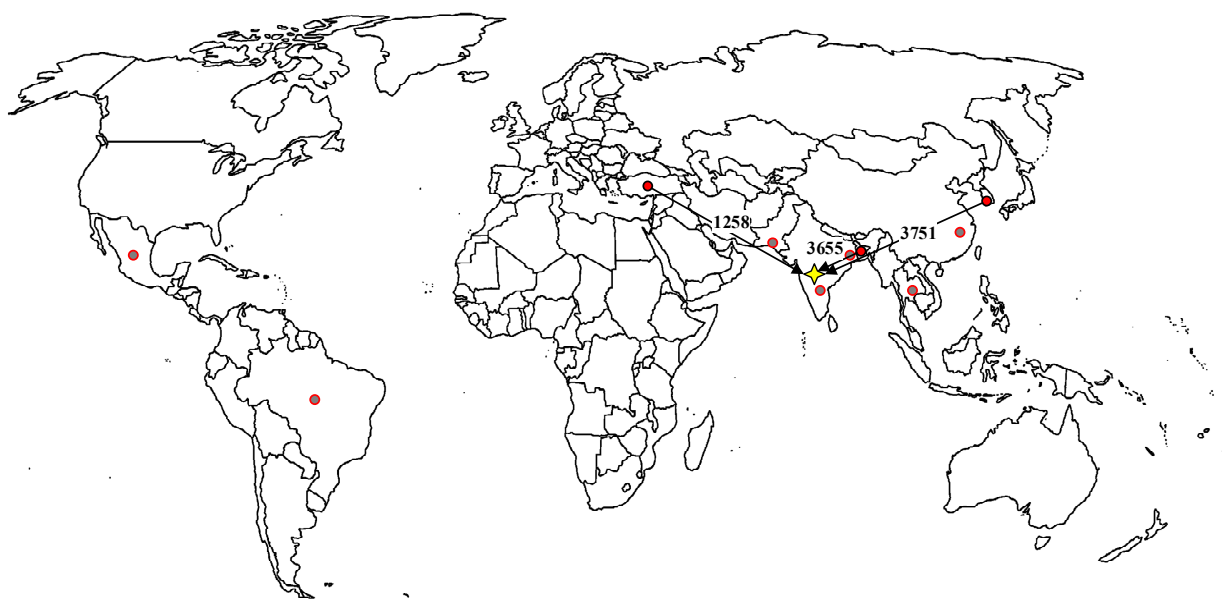

- Selected supplier location • Not selected supplier location $\diamond$ Existing Manufacturer

Figure 3. Final decision based on decision makers preferences.

\section{Conclusion and Future Suggestions}

This paper introduced a novel possibilistic fuzzy environment for resilient supplier selection and order allocation considering new resilience criteria (supply density, transit time and resilience index score) for the selection of suppliers. For this purpose, an interactive fuzzy multi-objective programming approach is introduced to reduce uncertainties inherent in the supplier selection decision. 
A six-step solution methodology is designed to solve the proposed uncertain multi-objective model and a numerical case example is provided to show the applicability of the proposed model in a real situation.

This study significantly helps the practitioners who are trying to consider resilience in their supply network. The research results show the importance of supplier's location in order to minimize disruption risks. Furthermore, the proposed model will help the managers to effectively evaluate and select a suitable set of suppliers while considering cost and resilience simultaneously. Moreover, the proposed possibilistic fuzzy based solution methodology will be helpful for practitioners and academicians to tackle cognitive and stochastic uncertainties related to supplier evaluation and selection problem. This study also helps the academicians to analyze the importance of resilient supply networks under disruption risks. Additionally, the proposed multi-objective possibilistic fuzzy-based approach can be useful in another area of supply chain optimization.

Although this research gained important insights from the implementation of proposed resilience criteria and solution methodology, there are some limitations which may be considered in future research. This paper assumed triangular fuzzy numbers for model parameters, it will be interesting to compare the research results with other fuzzy numbers such as trapezoidal in future studies. Furthermore, this research only considered a disruption of the location where suppliers are located. However, it will be important to consider the disruption of transport links between suppliers and buyers. Another interesting possible direction for future research is to extend the proposed model to multi-commodity and multi-period planning horizon. Lastly, the analysis result indicates that economic networks are denser network and they may be vulnerable to disruption risks, it will be valuable to further investigate the relationship between the economic network (denser network) and disruption risks.

Author Contributions: Conceptualization, S.I.M.; Methodology, M.S.M.; Software, M.B.R.; Supervision, S.M.Q.; Validation, S.M.Q.; Writing_original draft, S.I.M.; Writing—review \& editing, M.W.I.

Acknowledgments: This research was supported by the Higher Education Commission of Pakistan through the Startup Research Grant Program (SRPG\#1299 and SRGP\#1335).

Conflicts of Interest: The authors declare no conflict of interest.

\section{References}

1. Schoenherr, T.; Modi, S.B.; Benton, W.C.; Carter, C.R.; Choi, T.Y.; Larson, P.D.; Leenders, M.R.; Mabert, V.A.; Narasimhan, R.; Wagner, S.M. Research Opportunities in Purchasing and Supply Management. Int. J. Prod. Res. 2012, 50, 4556-4579. [CrossRef]

2. Kim, J.S.; Jeon, E.; Noh, J.; Park, J.H. A Model and an Algorithm for a Large-Scale Sustainable Supplier Selection and Order Allocation Problem. Mathematics 2018, 6, 325. [CrossRef]

3. Mari, I.S.; Lee, Y.H.; Memon, M.S.; Park, Y.S.; Kim, M. Adaptivity of Complex Network Topologies for Designing Resilient Supply Chain Networks. Int. J. Ind. Eng. 2015, 22, 102-116.

4. Tang, C.; Tomlin, B. The Power of Flexibility for Mitigating Supply Chain Risks. Int. J. Prod. Econ. 2008, 116, 12-27. [CrossRef]

5. Wang, C.-N.; Nguyen, V.T.; Thai, H.T.N.; Tran, N.N.; Tran, T.L.A. Sustainable Supplier Selection Process in Edible Oil Production by a Hybrid Fuzzy Analytical Hierarchy Process and Green Data Envelopment Analysis for the Smes Food Processing Industry. Mathematics 2018, 6, 302. [CrossRef]

6. Wang, X.; Herty, M.; Zhao, L. Contingent Rerouting for Enhancing Supply Chain Resilience from Supplier Behavior Perspective. Int. Trans. Oper. Res. 2016, 23, 775-796. [CrossRef]

7. Chopra, S.; Sodhi, M. Reducing the Risk of Supply Chain Disruptions. Mit Sloan Manag. Rev. 2014, 55, 72-80.

8. Barroso, A.P.; Machado, V.H.; Barros, A.R.; Machado, V.C. Toward a Resilient Supply Chain with Supply Disturbances. Presented at the 2010 IEEE International Conference on Industrial Engineering and Engineering Management (IEEM), Macao, China, 7-10 December 2010.

9. Torabi, S.A.; Baghersad, M.; Mansouri, S.A. Resilient Supplier Selection and Order Allocation under Operational and Disruption Risks. Transp. Res. Part E: Logist. Transp. Rev. 2015, 79, 22-48. [CrossRef] 
10. Carvalho, H.; Azevedo, S.G.; Cruz-Machado, V. Agile and Resilient Approaches to Supply Chain Management: Influence on Performance and Competitiveness. Logist. Res. 2012, 4, 49-62. [CrossRef]

11. Ribeiro, P.J.; Barbosa-Povoa, A. Supply Chain Resilience: Definitions and Quantitative Modelling Approaches-a Literature Review. Comput. Ind. Eng. 2018, 115, 109-122. [CrossRef]

12. Parkouhi, V.S.; Ghadikolaei, A.S. A Resilience Approach for Supplier Selection: Using Fuzzy Analytic Network Process and Grey Vikor Techniques. J. Clean. Prod. 2017, 161, 431-451. [CrossRef]

13. Hosseini, S.; Al Khaled, A. A Hybrid Ensemble and Ahp Approach for Resilient Supplier Selection. J. Intell. Manuf. 2016, 1-22. [CrossRef]

14. Sahu, A.K.; Datta, S.; Mahapatra, S.S. Evaluation and Selection of Resilient Suppliers in Fuzzy Environment: Exploration of Fuzzy-Vikor. Benchmarking Int. J. 2016, 23, 651-673. [CrossRef]

15. López, C.; Ishizaka, A. A Hybrid Fcm-Ahp Approach to Predict Impacts of Offshore Outsourcing Location Decisions on Supply Chain Resilience. J. Bus. Res. 2017. [CrossRef]

16. Sabouhi, F.; Pishvaee, M.S.; Jabalameli, M.S. Resilient Supply Chain Design under Operational and Disruption Risks Considering Quantity Discount: A Case Study of Pharmaceutical Supply Chain. Comput. Ind. Eng. 2018, 126, 657-672. [CrossRef]

17. Jabbarzadeh, A.; Fahimnia, B.; Sabouhi, F. Resilient and Sustainable Supply Chain Design: Sustainability Analysis under Disruption Risks. Int. J. Prod. Res. 2018, 1-24. [CrossRef]

18. Wang, T.-K.; Zhang, Q.; Chong, H.; Wang, X. Integrated Supplier Selection Framework in a Resilient Construction Supply Chain: An Approach Via Analytic Hierarchy Process (Ahp) and Grey Relational Analysis (Gra). Sustainability 2017, 9, 289. [CrossRef]

19. Hosseini, S.; Barker, K. A Bayesian Network Model for Resilience-Based Supplier Selection. Int. J. Prod. Econ. 2016, 180, 68-87. [CrossRef]

20. Haldar, A.; Ray, A.; Banerjee, D.; Ghosh, S. A Hybrid Mcdm Model for Resilient Supplier Selection. Int. J. Manag. Sci. Eng. Manag. 2012, 7, 284-292. [CrossRef]

21. Haldar, A.; Ray, A.; Banerjee, D.; Ghosh, S. Resilient Supplier Selection under a Fuzzy Environment. Int. J. Manag. Sci. Eng. Manag. 2014, 9, 147-156. [CrossRef]

22. Sawik, T. Selection of Resilient Supply Portfolio under Disruption Risks. Omega 2013, 41, 259-269. [CrossRef]

23. Sawik, T. Joint Supplier Selection and Scheduling of Customer Orders under Disruption Risks: Single vs. Dual Sourcing. Omega 2014, 43, 83-95. [CrossRef]

24. Yilmaz-Börekçi, D.; Say, A.İ.; Rofcanin, Y. Measuring Supplier Resilience in Supply Networks. J. Chang. Manag. 2015, 15, 64-82. [CrossRef]

25. Rajesh, R.; Ravi, V. Supplier Selection in Resilient Supply Chains: A Grey Relational Analysis Approach. J. Clean. Prod. 2015, 86, 343-359. [CrossRef]

26. Tiwari, R.N.; Dharmar, S.; Rao, J.R. Fuzzy Goal Programming_An Additive Model. Fuzzy Sets Syst. 1987, 24, 27-34. [CrossRef]

27. Werners, B.M. Aggregation Models in Mathematical Programming. In Mathematical Models for Decision Support; Springer: Berlin/Heidelberg, Germany, 1988; pp. 295-305.

28. Memon, M.S.; Lee, Y.H.; Mari, S.I. Group Multi-Criteria Supplier Selection Using Combined Grey Systems Theory and Uncertainty Theory. Expert Syst. Appl. 2015, 42, 7951-7959. [CrossRef]

29. Memon, M.S.; Mari, S.I.; Shaikh, F.; Shaikh, S.A. A Grey-Fuzzy Multiobjective Model for Supplier Selection and Production-Distribution Planning Considering Consumer Safety. Math. Probl Eng. 2018, 2018, 5259876. [CrossRef]

30. Holling, C.S. Resilience and Stability of Ecological Systems. Annu. Rev. Ecol. Syst. 1973, 4, 1-23. [CrossRef]

31. Hamel, G.; Valikangas, L. The Quest for Resilience. Revista Icade Revista de las Facultades de Derecho y Ciencias Económicas y Empresariales 2004, 62, 355-358.

32. Sheffi, Y. The Resilient Enterprise: Overcoming Vulnerability for Competitive Advantage; MIT Press: Cambridge, MA, USA, 2005.

33. Sutcliffe, M.K.; Vogus, T.J. Organizing for Resilience. Posit. Organ. Scholarsh. Found. New Discip. 2003, 94, 110.

34. Woods, D.D. Four Concepts for Resilience and the Implications for the Future of Resilience Engineering. Reliab. Eng. Syst. Saf. 2015, 141, 5-9. [CrossRef]

35. Zhalechian, M.; Torabi, S.A.; Mohammadi, M. Hub-and-Spoke Network Design under Operational and Disruption Risks. Transp. Res. Part E Logist. Transp. Rev. 2018, 109, 20-43. [CrossRef] 
36. Falasca, M.; Zobel, C.W.; Cook, D. A Decision Support Framework to Assess Supply Chain Resilience. Presented at the 5th International ISCRAM Conference, Washington, DC, USA, 4-7 May 2008.

37. Mari, S.I.; Lee, Y.H.; Memon, M.S. Complex Network Theory-Based Approach for Designing Resilient Supply Chain Networks. Int. J. Logist. Syst. Manag. 2015, 21, 365-384. [CrossRef]

38. Priya Datta, P.; Christopher, M.; Allen, P. Agent-Based Modelling of Complex Production/Distribution Systems to Improve Resilience. Int. J. Logist. Res. Appl. 2007, 10, 187-203. [CrossRef]

39. Azevedo, S.G.; Govindan, K.; Carvalho, H.; Cruz-Machado, V. Gresilient Index to Assess the Greenness and Resilience of the Automotive Supply Chain. Discuss. Pap. Bus. Econ. 2011, 8. [CrossRef]

40. Miller-Hooks, E.; Zhang, X.; Faturechi, R. Measuring and Maximizing Resilience of Freight Transportation Networks. Comput. Oper. Res. 2012, 39, 1633-1643. [CrossRef]

41. Tang, C.S. Robust Strategies for Mitigating Supply Chain Disruptions. Int. J. Logist. Res. Appl. 2006, 9, $33-45$. [CrossRef]

42. Sheffi, Y.; Rice, J.B., Jr. A Supply Chain View of the Resilient Enterprise. Mit Sloan Manag. Rev. 2005, 47, 41.

43. Mari, S.I.; Lee, Y.H.; Memon, M.S. Sustainable and Resilient Supply Chain Network Design under Disruption Risks. Sustainability 2014, 6, 6666-6686. [CrossRef]

44. Pramanik, D.; Haldar, A.; Mondal, S.C.; Naskar, S.K.; Ray, A. Resilient Supplier Selection Using Ahp-Topsis-Qfd under a Fuzzy Environment. Int. J. Manag. Sci. Eng. Manag. 2017, 12, 45-54. [CrossRef]

45. Sen, D.K.; Datta, S.; Mahapatra, S.S. Dominance Based Fuzzy Decision Support Framework for G-Resilient (Ecosilient) Supplier Selection: An Empirical Modelling. Int. J. Sustain. Eng. 2017, 10, 338-357. [CrossRef]

46. Parkouhi, S.V.; Ghadikolaei, A.S.; Lajimi, H.F. Resilient Supplier Selection and Segmentation in Grey Environment. J. Clean. Prod. 2019, 207, 1123-1137. [CrossRef]

47. Papadakis, I.S. Financial Performance of Supply Chains after Disruptions: An Event Study. Supply Chain Manag. Int. J. 2006, 11, 25-33. [CrossRef]

48. FMGlobal. The 2015 FM Global Resilience Index Annual Report. Available online: https:/ / www.fmglobal. com/assets/pdf/Resilience_Methodology.pdf (accessed on 3 July 2018).

49. Mari, S.I.; Lee, Y.H.; Memon, M.S. Sustainable and Resilient Garment Supply Chain Network Design with Fuzzy Multi-Objectives under Uncertainty. Sustainability 2016, 8, 1038. [CrossRef]

50. Min, H.; Zhou, G. Supply Chain Modeling: Past, Present and Future. Comput. Ind. Eng. 2002, 43, $231-249$. [CrossRef]

51. Jiménez, M.; Arenas, M.; Bilbao, A.; Rodrı, M.V. Linear Programming with Fuzzy Parameters: An Interactive Method Resolution. Eur. J. Oper. Res. 2007, 177, 1599-1609. [CrossRef]

52. Tayyab, M.; Sarkar, B.; Yahya, B. Imperfect Multi-Stage Lean Manufacturing System with Rework under Fuzzy Demand. Mathematics 2019, 7, 13. [CrossRef]

53. Li, X.; Chien, C.F.; Yang, L.; Gao, Z. The Train Fueling Cost Minimization Problem with Fuzzy Fuel Prices. Flex. Serv. Manuf. J. 2014, 26, 249-267. [CrossRef]

54. Selim, H.; Ozkarahan, I. A Supply Chain Distribution Network Design Model: An Interactive Fuzzy Goal Programming-Based Solution Approach. Int. J. Adv. Manuf. Technol. 2008, 36, 401-418. [CrossRef]

55. Babar Ramzan, M.; Qureshi, S.M.; Mari, S.I.; Memon, M.S.; Mittal, M.; Imran, M.; Iqbal, M.W. Effect of Time-Varying Factors on Optimal Combination of Quality Inspectors for Offline Inspection Station. Mathematics 2019, 7, 51. [CrossRef]

56. Sarkar, B.; Tayyab, M.; Choi, S.K. Product Channeling in an O2O Supply Chain Management as Power Transmission in Electric Power Distribution Systems. Mathematics 2019, 7, 4. [CrossRef]

(C) 2019 by the authors. Licensee MDPI, Basel, Switzerland. This article is an open access article distributed under the terms and conditions of the Creative Commons Attribution (CC BY) license (http://creativecommons.org/licenses/by/4.0/). 